\title{
A FLOW MANOSTAT FOR VARIOUS PURPOSES, INCLUDING THE CANDY TEST
}

\author{
By Max J. Proffitt
}

\section{ABSTRACT}

The flow manostat described in this paper is virtually a sensitive pressure-reducer in which the valve unit consists of a knife-edged circular orifice which is converted into an annular opening by means of a coaxial tapered core that floats upon a liquid surface which is depressed through contact with the gas at the regulated reduced pressure. Any change in the regulated pressure produces an axial movement of the core, thus expanding or contracting the area of the annular opening by an amount which is just sufficient to compensate approximately the effects of the change in the service pressure that induced the change in the regulated pressure. To minimize friction, the major diameter of the spindle or tapered part of the core is made slightly less than the diameter of the orifice. This allows the spindle to move its full length through the orifice without touching the edges of the orifice. Each valve unit has only a short range of variability in throughput capacity. Any reasonable capacity outside of this range can be obtained by substituting a valve unit of appropriate size in the same manostat. Each valve unit comprises an orifice plate with knife-edged opening (or else a pair of such plates), together with a properly fitting core having one spindle or two as required. The volume of flow always is governed by the discharge characteristics of the nozzle or fixed group of simultaneously operating nozzles served by the manostat. Any change in these characteristics will involve readjustment of the regulated pressure.

An experimental anostat equipped with a double, self-balancing valve unit conforming approximately with this design reduced a gas service pressure varying between the limits of 104 and $164 \mathrm{~mm}$ of water to a regulated pressure of $49.6 \pm 0.5 \mathrm{~mm}$ of water, while serving three burners consuming a total of about 8 cubic feet of gas per hour.

\section{CONTENTS}

I. Introduction

II. General description and theory of operation

III. Practical application and results obtained

IV. Summary _.

V. References_... 155 


\section{Journal of Research of the National Bureau of Standards}

\section{INTRODUCTION}

The need of operating a gas burner at approximately a constant rate of heat output frequently is encountered in analytical procedures and in many other types of laboratory work. This requires the maintenance of virtually a steady pressure differential between the gas at the nozzle entrance of the burner and the atmosphere in which the burner is operating. Frequently the gas service pressure is subject to a degree of fluctuation which practically prohibits such procedures. The fluctuations come partly from variations in the pressure of the gas as it is delivered to thelaboratory and partly from the intermittent drawing of the gas from the various outlets in the laboratory. Usually the upper and lower limits of the fluctuation are fairly well defined and the most frequent variation occurs over a smaller range of pressure differentials. The simplest means of meeting such circumstances is to provide a pressure regulator for the one particular burner or group of burners which is required to operate at a steady rate of heat output. Some of the commercial devices that are intended to maintain a constant pressure at the burner regardless of the pressure variations in the gas supply have rather consistently failed to perform the service, not only because of mechanical defects in their construction, but also because they were devised apparently without adequate attention to the principles involved. One of the simplest of these devices consists of a stopcock type of throttle linked to the bell of a small gasometer, which many have found aggravates rather than lessens the difficulty. To fill the need of an instrument which will function with the precision requisite for numerous purposes, including candy tests, the flow manostat described below was designed. Its field of usefulness, however, is not confined to the regulation of gas-burner performance. It can be used for the regulation of other gas flows of similar rates that are governed by nozzles, by capillaries, by tubular flow-meters, or by similar means under suitable pressures and pressure differentials.

\section{GENERAL DESCRIPTION AND THEORY OF OPERATION}

A variable annular orifice, $U$, constructed as indicated diagrammatically in figures 1 and 2, was chosen as the most feasible form of throttle valve among several that were considered for the purpose of regulating the flow of the gas through the manostat without excessive pressure losses. When carefully designed and constructed, this very simple form of restrictive orifice not only can be made mechanically practical but, as was demonstrated in numerous preliminary experiments, it is capable of yielding a performance that conforms approximately with most of the other requirements (p. 150). As compared, however, with an iris diaphragm, which apparently should present the most favorable form of opening for the purpose except for the mechanical difficulties involved in its construction and operation, the annular orifice has less latitude of practical variability in throughput capacity and presumably less favorable discharge characteristics. The supposed defects in discharge characteristics are attributed to the fact that the annular orifice presents much narrower clearances for the passage of the gas, and much greater areas of passage surfaces, per unit of cross-sectional area of opening, especially at the minimum throughput capacities. Presumably these drawbacks could prove 
serious where deposits from the gas may be considerable, but in practice no trouble has been encountered.

The annulus is formed by providing a core in a circular knife-edged hole in a thin plate, $O P$, figure 1 , which separates the entrance chamber, $E$, of the manostat from the expansion chamber, $R$, in which the regulated pressure differential, $\Delta h_{r}$, is set up as back-pressure derived principally from the resistance of the burner nozzles at $N$. In operation, the annulus is varied automatically as to width by means of the axial movement of its core. The core comprises a tapered spindle, $V$, arranged to float, coaxially with the hole in the plate, $O P$, upon a "depressed hydrostatic column" which is in contact with the gas in

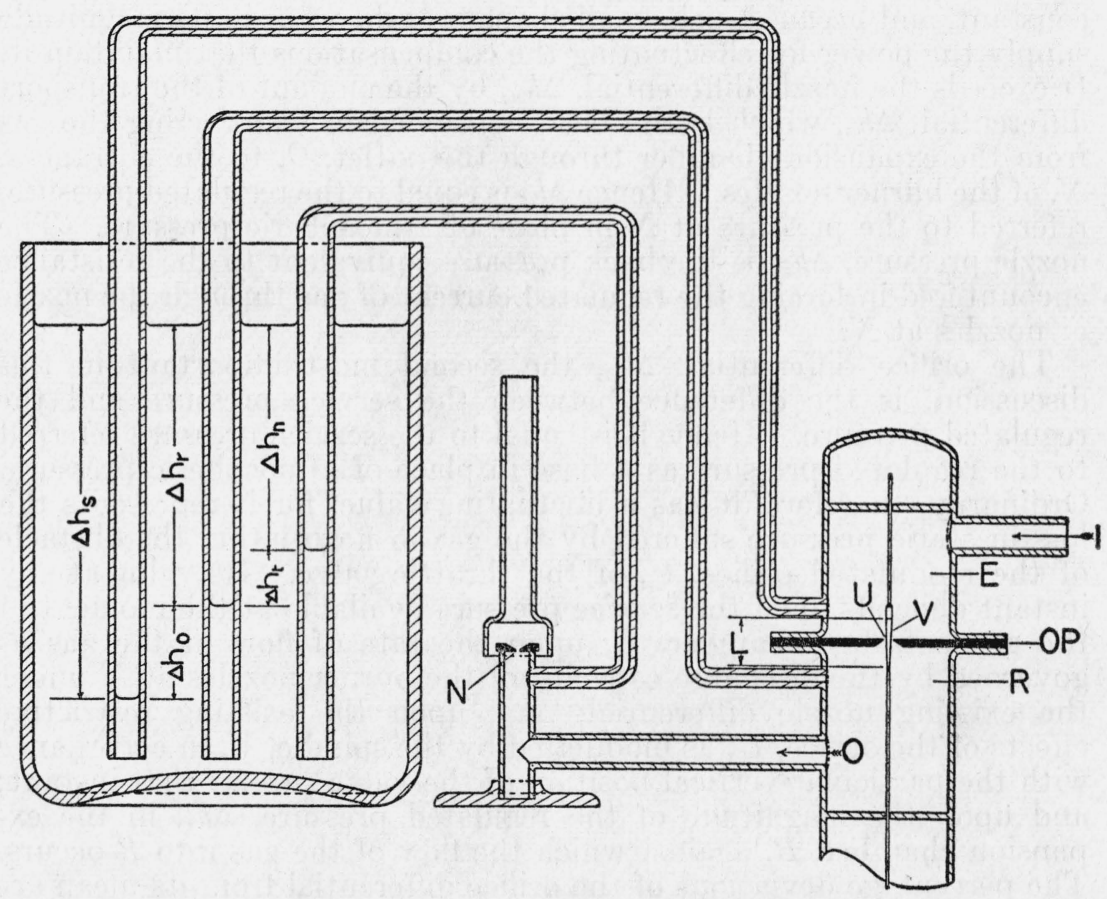

Figure 1.-Relations among pressure differentials, flow-manostat valve, and gas burner nozzle.

For detailed description, see p. 146.

the expansion chamber and, through a submerged connection, is balanced against another hydrostatic column of the same liquid in contact with the atmosphere. In other words, the spindle in effect floats upon a liquid surface which, because of the pressure of the gas in the expansion chamber above it, is depressed relative to the surface of the main body of the liquid in a connecting reservoir that is open to the atmosphere. The essential features of the arrangement are illustrated at $A$ and $B$ in figure 2 .

Operation of the manostat sets up various static pressure differentials in the current of gas passing through it. Some of these can be used to advantage in explaining the action and performance of the instrument. To illustrate visually the interrelationships of the 
differentials of principal interest, and the relationships of each to the apparatus, reference again is made to figure 1, directing special attention to the gages represented in the left-hand part of the diagram. Of the five differentials represented, the service differential, $\Delta h_{\mathrm{s}}$, the regulated differential, $\Delta h_{\mathrm{r}}$, and the nozzle differential, $\Delta h_{n}$, are all referred to atmospheric pressure as the base, while the two remaining are referred to other bases. Notice that in the last sentence and in most of the remaining text the descriptive terms for these differentials are abridged to avoid repetition of the words not needed to identify the values.

The regulated differential is the most important in the present discussion because the purpose of the manostat is to keep it virtually constant, and because such small changes as do occur in its magnitude supply the power for effectuating the compensations that maintain it. It exceeds the nozzle differential, $\Delta h_{n}$, by the amount of the transport differential, $\Delta h_{t}$, which is the head consumed in transferring the gas from the expansion chamber through the outlet, $O$, to the entrances, $N$, of the burner nozzles. Hence $\Delta h_{t}$ is equal to the regulated pressure, referred to the pressure at $N$ in place of atmospheric pressure. The nozzle pressure, $\Delta h_{n}$, is the back pressure equivalent to the resistance encountered in forcing the regulated current of gas through the nozzle or nozzles at $N$.

The orifice differential, $\Delta h_{o}$, the second most important in this discussion, is the difference between the service pressure and the regulated pressure. Hence it is equal to the service pressure referred to the regulated pressure as a base in place of atmospheric pressure. Ordinarily, therefore, it has a fluctuating value, for it represents the loss in static pressure suffered by the gas in negotiating the obstacle of the modulated orifice, $U$, of the throttle valve. Its value at any instant depends upon the service pressure available at the moment in the gas entrance chamber, $E$; upon the rate of flow of the gas as governed by the discharge capacity of the burner nozzles at $N$ under the existing nozzle differential, $\Delta h_{n}$; upon the existing restrictive effects of the orifice, $U$, as modulated by the spindle, $V$, in accordance with the particular vertical position of the valve core at that instant; and upon the magnitude of the regulated pressure, $\Delta h_{r}$, in the expansion chamber, $R$, against which the flow of the gas into $R$ occurs. The percentage deviations of the orifice differential from its mean are bound to exceed the percentage deviations of the service-pressure differential from the mean service differential. This is evident from the fact that the service differential, as the diagram indicates, is represented by

$$
\Delta h_{s}=\Delta h_{o}+\Delta h_{r} ;
$$

for most of the variability in $\Delta h_{s}$ has to be absorbed by the orifice differential, so long as $\Delta h_{r}$ is virtually constant and the mean value of $\Delta h_{o}$ always is smaller than the mean value of the service differential.

Construction diagrams, representing generalized vertical sections of the manostat alone, in two slightly different forms, are presented at $A$ and $B$ in figure 2. The form illustrated at $B$ has a single throttle valve, that illustrated at $A$ has a double valve arranged as indicated in the enlarged section at $C$. In sections $B$ and $A$, the float wells, $F W$, contain the hydrostatic columns which support the orifice cores 

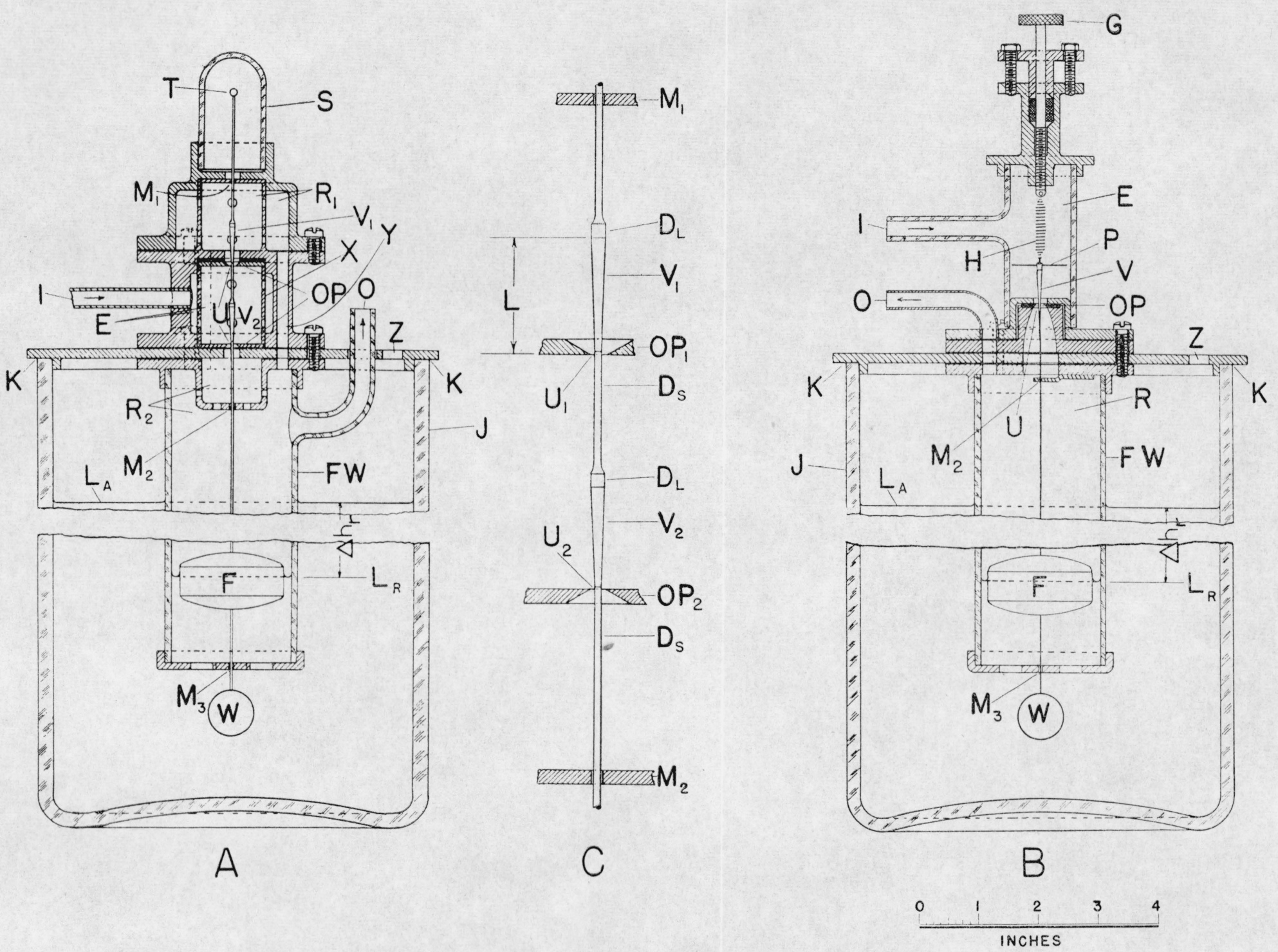

FIGURE 2.-Construction of flow manostats with double and single modulator valves, respectively. $A$, manostat with balanced double valve; $\boldsymbol{B}$, manostat with spring-balanced single valve; $\boldsymbol{C}$, enlarged view of valve, $\mathrm{X} 3$. 469958 (Face p. 146) For detailed descript ion of apparatus, see p. 146 . 
through the floats, $F$, which are stabilized by the ballast weights, $W$. Through contact with the gas in the expansion chambers, $R$ and $R_{2}$, respectively, in the upper ends of the float wells, the surfaces of these columns (at the levels $L_{R}$ ) are depressed relative to the surfaces (at the levels $L_{A}$ ) of the main bodies of the liquid in the annular reservoir spaces between the float wells and the walls, $J$, of the vessels in which the float wells are immersed. The vertical distance through which the surfaces of the columns is depressed represents the magnitude of the regulated pressure differential, $\Delta h_{r}$, in terms of the liquid used. The spindle, $V$, in view $B$, is retained in a position coaxial with the orifice, $U$, in the plate, $O P$, in part by the pull of the suspension spring, $H$, against the weight of the core, float, and ballast assembly, and in part by the bearings or retaining eyes, $M_{2}$, and $M_{3}$, through which the tail wire connecting the assembly is threaded. The core comprising the two spindles, $V_{1}$ and $V_{2}$, in view $A$, is similarly retained in the proper coaxial position by means of the slip bearings, $M_{1}$ and $M_{3}$, in which the stems of the assembly slide freely without appreciable radial play. The spindle, $V$, in view $B$, preferably should be provided with a stem at the top, to slide in a bearing as at $M_{1}$ in view $A$, because of the difficulty in keeping the spring connections centered properly without it.

With respect to its shape, each spindle has the three parts illustrated in view $C$ of figure 2-regardless of whether the throttle valve is single or double. The upper cylindrical part, $D_{L}$, has a minimum length approximating the thickness of the orifice plate, $O P$, and a diameter which is just enough smaller than the bore of the orifice, $U$, to let the part enter the opening without ever touching the thin edges of the orifice with any small radial play the bearings may allow. The conically tapered main part (marked $V_{1}, V_{2}$, in this view), of a length, $L$, between 10 and $20 \mathrm{~mm}$, has a major diameter equal to the diameter of $D_{L}$ and a minor diameter not greater than one-half of the major diameter. The lower cylindrical part, $D_{S}$, having the same diameter as the minor diameter of the tapered part, is relatively long for the reason that, preferably, it should be continuous with the stem of the core below the spindle. The stem of the core above the spindle preferably should be of the same diameter as the other parts of the stem, just as the drawing indicates. In any compound core for a doublevalve manostat, the distance between any corresponding parts of the two component spindles is precisely equal to the distance between the knife edges of the orifices, $U_{1}$ and $U_{2}$, when the plates, $O P_{1}$ and $O P_{2}$, are properly mounted with the flat side of each orifice plate facing the entrance chamber, $E$, and with the beveled side facing an expansion chamber, $R_{1}$ or $R_{2}$. For this reason the compound core is made all in one piece, as illustrated at $C$, and the orifice plates are spaced precisely the correct distance apart by means of the perforated spreader ring, $X$, which is pressed into the entrance chamber, $E$, as illustrated in view $A$ of figure 2. The orifice plates are approximately $1.6 \mathrm{~mm}$ thick, and the orifices are required to be precisely circular in form. The knife edges of the orifices are required to be clean-cut and polished and not thicker than $0.1 \mathrm{~mm}$, the edges of the orifices on the exit side being beveled at an angle of $60^{\circ}$ with the orifice axis. An orifice plate, or a pair of orifice plates, as the valve may require, together with the simple or compound core, respectively, made for 
operating in accordance "with"the"specifications given above, constitute a throttle valve unit. Since both parts are removable, the valve unit is replaceable as a whole. Thus a wide range of throughput capacity can be made readily available by providing a number of valve units in an assortment of sizes that are properly related to each other to provide suitable overlapping of the individual short ranges of throughput capacity.

When the gas connection to the manostat is cut off and the servicepressure differential at the inlet, $I$, falls to zero, the liquid in the float well, $F W$, and the liquid in contact with the atmosphere in the reservoir space seek the same level of surface. As the liquid in $F W$ thus rises, it buoys the float upward until the ballast weight, $W$, coming into contact with the perforated bottom of the float well, stops the uplift of the core at the widest opening of the throttle valve. Then, upon opening the gas connection, the gas flows rapidly through the inlet, $I$, through the open throttle valve, through the chamber, $R$, and the connecting ducts, to the entrances of the burner nozzles (at $N$, in fig. 1). The resistance of the nozzles and the connecting ducts sets up a backpressure differential in chamber $R$ which at first exceeds the final regulated pressure differential, $\Delta h_{r}$, driving the surface of the liquid in $F W$ (fig. 2) below the level $L_{R}$. The resulting descent of the core momentarily closes the valve beyond the correctly modulated opening, allowing less than the correctly regulated current of gas to pass. At once the pressure in $R$ falls below the correct value of $\Delta h_{r}$, and the resulting rise of the liquid in $F W$ to a surface level above $L_{R}$ starts a train of repetitions of the whole cycle in which the amplitudes of variation become smaller and smaller until within a few seconds, at most, any small pressure variations still occurring in chamber $R$ come solely from the fluctuations of the service-pressure differential at the inlet, $I$.

Thus, after the manostat has settled down to steady operation, the annular orifice opening of the throttle valve is modulated continually and automatically through the action of the changes occurring in the regulated pressure, small as they are. The cross-sectional area of the orifice opening expands as the regulated pressure differential diminishes through any slackening of the current entering the expansion chamber following a decrease in the service pressure. Contrarywise, the opening contracts as these causal actions reverse. The distance of travel, $l$, in the spindle's response to a change in $\Delta h_{r}$ is bound to be less than the change in $\Delta h_{r}$ as measured between the levels $L_{A}$ and $L_{R}$ of the hydrostatic liquid. The amount of the difference at equilibrium depends upon the ratio of the inside cross-sectional area of the float well to the cross-sectional area of the hydrostatic reservoir. The amount of the working difference between the distance, $l$, and the change in $\Delta h_{r}$ generally tends to be greater than the equilibrium value, owing to the lag of response. The degree of the lag depends in part upon the viscosity of the hydrostatic liquid and in part upon the dimensions and other characteristics of the ports or ducts provided for the flow of the liquid into and out of the float well. But it depends chiefly, apparently, upon the inertia of the whole system in relation to the magnitude of the forces acting. Hence the influence of the lag can be predetermined (within certain limiting values) in setting up the design of the details of the construction of the apparatus. A suitable construction will prevent hunting in the automatic modulation 
of the restrictive orifices. In particular it will serve to damp any probable resonance between the surge effects of the liquid and the fluctuations in the service pressure, $\Delta h_{s}$. This damping can be effectuated by changing the mass of the ballast weight, $W$, by restricting the openings of the ports at the foot of the float well (as, for example, by bushing the openings, by lengthening the ducts, etc.), and especially by compounding the reservoir. Methods of compounding a reservoir are suggested on pages 151 and 152.

This primary actuation of the modulation of the orifice opening by means of the regulated pressure differential will be called the "column effect." With the "balanced" valves illustrated in figure 2, it is virtually the only effect of consequence that is operative. But with a single unbalanced valve arrangement, like that illustrated in figure 1 , where the core is supported solely by the float, as at $A$ in figure 2, it is apparent that the vertical position of the spindle is determined, in part, by an additive secondary phenomenon which will be called the "piston effect." This is the tendency of the spindle to react directly to the pressure change occurring in the orifice differential, $\Delta h_{o}$. The action of this effect upon the modulation is equivalent to the change which would result from altering the ballast weight, $W$, by the addition or removal of mass.

The operation of the piston effect can be described roughly as follows. The pressure of the orifice differential bears directly upon the spindle itself as though $V$ (fig. 1) were a piston of variable effective area which expands as the spindle descends into the orifice opening. When the orifice differential is increasing, it tends to drive the spindle downward against the buoyancy of the float. As the spindle sinks, the driving force bearing upon the spindle tends to be augmented continuously. The gain in the driving force is due not only to the initial rate of increase in $\Delta h_{o}$, but also to the expansion of the effective piston area on which the pressure bears and to that increment of $\Delta h_{0}$ which is due to the contraction of the orifice area. At the same time, any downward movement of the spindle resulting from this force, and not from the column effect, is increasingly opposed by the buoyancy of the float by which the float resists further immersion in the liquid. In addition, any downward movement of the spindle tending to produce greater immersion of the float tends to be curtailed or even overmatched almost at once by the counter-response of the column effect resulting from the contraction of the orifice. When the orifice differential is diminishing, it tends to let the buoyancy of the float lift the spindle, thereby reversing the other tendencies mentioned above. Hence, with favorable construction of the apparatus, the piston effect could be utilized to implement the modulation of the orifice opening and thus further reduce the variation of the regulated pressure.

Utilization of the piston effect for this purpose would depend upon having the cross-sectional area of the float, $F$, properly related to the taper and the cross-sectional area of the spindle at its major diameter. This relationship is influenced by the density of the hydrostatic liquid and by other conditions. If the ratios are all appropriate, the response to the piston effect will tend to augment or diminish the degree of immersion of the float in the liquid (and thereby depress or elevate the position of the spindle in the orifice) just sufficiently to 
perform a major portion of the modulation necessary to counteract any intolerable change in the magnitude of $\Delta h_{r}$. Then a relatively small change in the length of the hydrostatic column by which the float is supported, coming gradually, will complete the modulation. Thus less variation in the value of $\Delta h_{r}$ should be involved than in any usual case where the modulation is brought about solely through the column effect. The result would be as though the instrument had foreseen the impending change in $\Delta h_{r}$ and had taken appropriate action to forestall most of the change at its source.

It is evident from the statement above that the problems of design and construction would be increased considerably by any rational utilization of the piston effect for the modulation of the orifice. Wider serviceability of the individual manostat, as well as greater freedom of design and construction, would be possible if the piston effect were eliminated. To this end two methods of counterbalancing the piston effect are illustrated in figure 2, on the assumption that one or the other should prove suitable for all usual circumstances.

In the construction illustrated in views $A$ and $C$ of figure 2, the piston effect is practically eliminated by causing the orifice differential to act in opposite directions upon the two rigidly connected spindles of a compound core. With this method of valve-balancing, the same float and ballast weight should serve for use with a variety of valve units, practically regardless of their differences in throughput capacity. As arranged in the diagram, the expansion chamber is of necessity divided into two sections, $R_{1}$ and $R_{2}$. The two sections are connected by ducts, one duct being indicated in sectional elevation at $Y$. (If desired, the outlet, $O$, could be taken from $R_{1}$ rather than from $R_{2}$ as indicated.) The indicator, $T$, attached to the upper end of the valve core, is always visible through the sight-glass, $S$, for observing the vertical position of the core during the adjustment and operation of the manostat.

In the construction indicated at $B$ in figure 2 , the piston effect is counterbalanced by the variable tension of the spring, $H$, as adjusted by the screw, $G$. The pointer, P, indicating the vertical position of the single spindle, $I$, is always visible through the glass walls of the entrance chamber, $E$. A manostat of this design can be constructed by hand in approximately the form indicated, using ordinary hand tools and materials that generally are available in laboratories. This is an especial advantage where the services of an instrument shop are not at hand. Moreover, single-valve manostats are practicable for smaller throughput capacities. In most other respects they appear to be inferior to the double-valve type.

In a double-valve manostat the regulation of the rate of flow of the gas into the expansion chamber through the operation of the column effect as described above (p. 149) can be made so effective that the back-pressure, $\Delta h_{\tau}$, is virtually constant with respect to its influence upon the heat output of the burners during any important interval of time. It can be so effective, indeed, that the percentage variation in the magnitude of $\Delta h_{\tau}$ amounts to only a small fraction of the percentage fluctuation usually encountered in the magnitude of the service-pressure differential as measured at the inlet, $\vec{I}$, or in the entrance chamber, $E$. Far less advantageous results were obtained when, in numerous experiments, the column effect was derived directly from the fluctuation of the service-pressure differential in 
place of the regulated pressure differential, notwithstanding that in the service-pressure fluctuation greater power is available for actuating the mechanism.

In the arrangements of the flow manostat illustrated in figure 2, there is no possibility of leakage of oil or other liquids from the apparatus, for there are no openings to the outside below the liquid level. When the liquid level is to be changed, the requisite quantity of oil is removed or introduced through the atmospheric opening ( $Z$, fig. 2) in the cover of the vessel, which serves as the support for the mechanism. To facilitate the transfer of the oil, a supply reservoir may be installed above the vessel on supports attached to the cover, with connections to a source of vacuum and to a vacuum-breaker cock. The supply reservoir should have an internal foot valve of the needle or plug type with its stem extending through a stuffing box at the top of the container. The foot valve should open into a transfer tube extending to a point near the bottom of the vessel, $J$. Instead of this, if preferred, the elevation of the mechanism with respect to the vessel, $J$, can be made adjustable. For example, the float, float well, and valve assembly can be supported on the cover of the vessel by means of a jacking device operated by a rack or a screw. Even when arranged as indicated, the effective level of the liquid can be reduced by inserting shims or other spacers at $K-K$ between the cover and the rim of the vessel.

In the constructions suggested in figure 2 , the float well is made of glass tubing approximately 2 inches in diameter, and the reservoir vessel in which the float well is suspended is a battery jar or similar glass container of not less than 35 square inches cross-sectional area, for the cross-sectional area of the reservoir should be large relative to that of the float well. Thus, in the constructions indicated, the thinwalled brass float, $F$, and the liquid column on which it rides are plainly visible from the outside for convenience in adjusting the manostat. The float is indicated as of approximately 1.75 inches outside diameter, a suitable size for a 2-inch float well. A reservoir of the kind indicated could be compounded very easily by means of a large hollow glass cylinder with open ends and a length somewhat less than the height of the jar inside. The cylinder should be placed inside the jar, with its walls surrounding the float well and with its lower end resting on the bottom of the jar with just enough clearance to allow passage of the liquid at a suitable rate of flow. The most favorable clearance could be found experimentally. The chosen clearance and the central location of the cylinder could be maintained by means of appropriate spreaders which could take the form of a light framework of metal.

\section{PRACTICAL APPLICATION AND RESULTS OBTAINED}

The principles of design and construction outlined in the foregoing, with particular reference to the double-valve device illustrated at $A$ in figure 2, were used as the general basis for constructing the experimental manostat illustrated in figure 3. However, this manostat differs from the form $A$ in a number of minor details. For example, both the reservoir and the float well are constructed of brass in place of glass. Hence neither the float nor the depressed hydrostatic column is visible. The glass gage at the right indicates the respective 
levels of the liquid in the reservoir and in the float well, and the pointer, $T$, in the sight-glass, $S$, indicates the position of the spindle, when the manostat is in operation. The reservoir comprises two vessels, $J_{1}$ and $J_{2}$, which are connected through the duct, $Q$. The small entrance chamber, constructed of thin sheet brass, is attached to the gas inlet duct, $I$, which extends through, and to a point below, the float-well cover, $F W$. Thus, the entrance chamber is suspended within the upper end of the float well. In this arrangement of the entrance chamber, both orifices of the balanced double valve discharge directly into the single expansion chamber comprising all of that part of the float well which is above the surface level of the depressed hydrostatic column when the manostat is in operation.

As first constructed, the experimental manostat had only the annular reservoir between the walls of $J_{1}$ and $F W$. The resulting variations in $\Delta h_{r}$ suggested that the port area at the foot of $F W$ was insufficient. After the port area was increased by the installation of the $U$-shaped ducts, $U D$, connecting the foot of the float-well sump with the sloping sides of $J_{1}$, surging of the liquid was observed under certain conditions. Installation of the secondary reservoir, $J_{2}$, from and to which the liquid flows through the duct, $Q$, at a rate differing from the rate for the primary reservoir, $J_{1}$, not only increased the reservoir area sufficiently to bring about adequate response of the modulator, as indicated by the smallness of the variations in the magnitude of $\Delta h_{r}$ resulting under the ordinary frequency of fluctuation in the gas service pressure, $\Delta h_{s}$, but also effectively damped the surging of the liquid under any conditions that have been encountered since. Serving three small burners with a total of probably about $8 \mathrm{ft}^{3} \mathrm{or}$ gas per hour for many hours, the flow manostat arranged as illustrated in figure 3 has maintained a regulated pressure of $\Delta h_{r}=49.6 \pm 0.5 \mathrm{~mm}$ of water column throughout, ${ }^{*}$, with very infrequent adjustments. The gas service pressure meanwhile has been subject to variation from 104 to $164 \mathrm{~mm}$ and the reverse, within periods of less than 5 minutes. The fluctuations between the limits of 110 and $138 \mathrm{~mm}$ of water column have been as many as six times a minute for short intervals.

The effectiveness and the precision of the regulation were evidenced also by the high degree of reproducibility attained in the time intervals consumed in carrying out candy tests in accordance with certain definite procedures that remain to be described in later papers. In properly grouped tests conducted without the use of the flow manostat under fluctuations of the service pressure such as those stated above, the variation in the cooking intervals, expressed as the percentage index of dispersion, $100 \sigma / a$, seldom was less than \pm 5 and often exceeded \pm 10 . In other words, the least-squares standard deviation in the time required to cook the candy generally exceeded 5 percent of the average time required for all of the tests in the group, and in many cases it exceeded the tolerance of \pm 8.7 percent allowed for the cooking interval in the original specifications of Hooker [2] and in some of the modified Hooker procedures [3], where the limits of the cooking interval are placed at 21 to 25 minutes. By "properly grouped" is meant the statistical assembly of the results of at least four tests carried out with the same apparatus and the same procedure, with no intervening adjustments of the burner or the spatial relations between the burner and the boiling-vessel. 


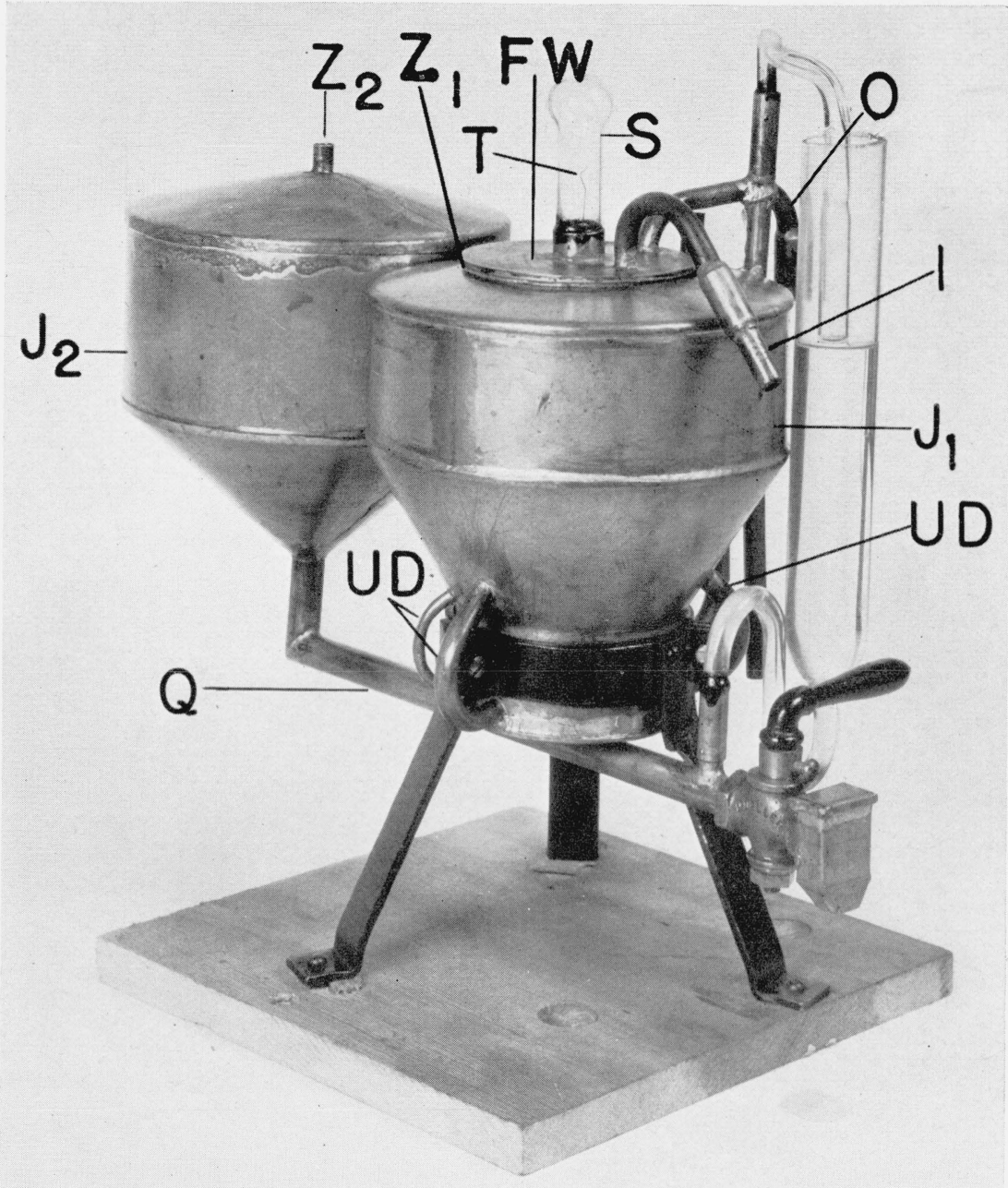

Figure 3.-Experimental flow-manostat.

For detailed description, see pp. 151 and 152. 
TABLE 1.-Typical variations obtained in the lengths of the cooking intervals of candy tests in which the gas pressure is regulated by means of the flow manostat

\begin{tabular}{|c|c|c|c|c|c|c|c|c|}
\hline \multicolumn{3}{|c|}{ GROUP I ${ }^{1}$} & \multicolumn{3}{|c|}{ GROUP II } & \multicolumn{3}{|c|}{ GROUP III } \\
\hline \multicolumn{3}{|c|}{ Sample weight, $100.0 \mathrm{~g}$} & \multicolumn{3}{|c|}{ Sample weight, $250.0 \mathrm{~g}$} & \multicolumn{3}{|c|}{ Sample weight, $250.0 \mathrm{~g}$} \\
\hline Test No. & Date & $\begin{array}{l}\text { Cooking in- } \\
\text { terval }\end{array}$ & Test No. & Date & $\begin{array}{l}\text { Cooking in- } \\
\text { terval }\end{array}$ & Test No. & Date & $\begin{array}{c}\text { Cooking in- } \\
\text { terval }\end{array}$ \\
\hline $\begin{array}{l}97 \\
98 \\
99 \\
100\end{array}$ & $\begin{array}{l}2-2-40 \\
2-8-40 \\
2-8-40 \\
2-8-40\end{array}$ & $\begin{array}{l}\text { Seconds } \\
1,172.6 \\
1,184.6 \\
1,157.5 \\
1,172.0 \\
\end{array}$ & $\begin{array}{l}105 \\
107 \\
110 \\
112\end{array}$ & $\begin{array}{l}4-1-40 \\
4-1-40 \\
4-2-40 \\
4-2-40\end{array}$ & $\begin{array}{l}\text { Seconds } \\
1,343 \\
1,339 \\
1,359 \\
1,334 \\
\end{array}$ & 106 & $\begin{array}{l}4-1-40 \\
4-1-40 \\
4-2-40 \\
4-2-40\end{array}$ & $\begin{array}{l}\text { Seconds } \\
1,326 \\
1,307 \\
1,324 \\
1,314 \\
\end{array}$ \\
\hline $\begin{array}{l}\text { A verage } \\
100 \sigma / a . .-\end{array}$ & - & $\begin{array}{c}1,171.7 \\
\pm 0.82\end{array}$ & $\begin{array}{l}\text { Average. } \\
100 \sigma / a_{-.-}\end{array}$ & - & $\begin{array}{l}1,344 \\
\quad \pm 0.70\end{array}$ & $\begin{array}{l}\text { Average } \\
100 \sigma / a .\end{array}$ & - & $\begin{array}{l}1,318 \\
\quad \pm 0.58\end{array}$ \\
\hline
\end{tabular}

\begin{tabular}{|c|c|c|c|c|c|c|c|c|}
\hline \multicolumn{3}{|c|}{ GROUP IV } & \multicolumn{3}{|c|}{ GROUP V } & \multicolumn{3}{|c|}{ GROUP VI } \\
\hline \multicolumn{3}{|c|}{ Sample weight, $250.0 \mathrm{~g}$} & \multicolumn{3}{|c|}{ Sample weight, $250.0 \mathrm{~g}$} & \multicolumn{3}{|c|}{ Sample weight, $250.0 \mathrm{~g}$} \\
\hline Test No. & Date & $\begin{array}{l}\text { Cooking in- } \\
\text { terval }\end{array}$ & Test No. & Date & $\begin{array}{l}\text { Cooking in- } \\
\text { terval }\end{array}$ & Test No. & Date & $\begin{array}{c}\text { Cooking in- } \\
\text { terval }\end{array}$ \\
\hline $\begin{array}{l}130 \\
132 \\
134 \\
136\end{array}$ & $\begin{array}{l}4-17-40 \\
4-17-40 \\
4-17-40 \\
4-18-40\end{array}$ & $\begin{array}{l}\text { Seconds } \\
1,198 \\
1,193 \\
1,194 \\
1,205\end{array}$ & $\begin{array}{l}133 \\
135 \\
137 \\
138\end{array}$ & $\begin{array}{l}4-17-40 \\
4-17-40 \\
4-18-40 \\
4-18-40\end{array}$ & $\begin{array}{l}\text { Seconds } \\
1,293 \\
1,296 \\
1,293 \\
1,286\end{array}$ & $\begin{array}{l}139 \\
141 \\
143 \\
145\end{array}$ & $\begin{array}{l}4-25-40 \\
4-26-40 \\
4-26-40 \\
4-27-40\end{array}$ & $\begin{array}{l}\text { Seconds } \\
1,263 \\
1,247 \\
1,231 \\
1,245\end{array}$ \\
\hline $\begin{array}{l}\text { Average } \\
100 \sigma / a\end{array}$ & - & $\begin{array}{l}1,197.5 \\
\quad \pm 0.39\end{array}$ & $\begin{array}{l}\text { Average } \\
100 \sigma / a .\end{array}$ & - & $\begin{array}{l}1,292 \\
\quad \pm 0.28\end{array}$ & $\begin{array}{l}\text { Average } \\
100 \sigma / a .\end{array}$ & & $\begin{array}{l}1,246 \\
\quad \pm 0.88\end{array}$ \\
\hline
\end{tabular}

\begin{tabular}{|c|c|c|}
\hline \multicolumn{3}{|c|}{ GROUP VII ${ }^{2}$} \\
\hline \multicolumn{3}{|c|}{ Sample weight, $250.0 \mathrm{~g}$} \\
\hline Test No. & Date & $\begin{array}{c}\text { Cooking in- } \\
\text { terval }\end{array}$ \\
\hline $\begin{array}{l}140 \\
142 \\
146 \\
150 \\
152 \\
154\end{array}$ & $\begin{array}{l}4-25-40 \\
4-26-40 \\
4-27-40 \\
5-1-40 \\
5-2-40 \\
5-2-40\end{array}$ & $\begin{array}{l}\text { Seconds } \\
1,317 \\
1,316 \\
1,317 \\
1,330 \\
1,346 \\
1,342\end{array}$ \\
\hline $\begin{array}{l}\text { Average. } \\
100 \sigma / a\end{array}$ & $\mid$ & $\begin{array}{l}1,328 \\
\quad \pm 0.90\end{array}$ \\
\hline
\end{tabular}

12 vessels used alternately.

22 vessels used, one in first three, $100 \sigma / a= \pm 0.043$; other in last three, $100 \sigma / a= \pm 0.51$.

In similar groups of tests using the flow manostat, the index of dispersion was usually less than \pm 1.0 , although the tests in any one group were seldom carried out consecutively and never all on the same day. This means that tests belonging to other groups and usually carried out in different vessels over different burners were interspersed with the tests in the group considered and that some of the tests were further separated in time by various other interruptions. But at the time of completing the final test in the groups listed in table 1 , no manual adjustment of the flow manostat had been made for 


\section{Journal of Research of the National Bureau of Standards}

more than a year. At the commencement of each run the gas was simply turned into the flow manostat, the burners were lighted, and usually the tests were begun within 1 to 30 minutes. In each of two of the groups, half of the tests were carried out in one boiling vessel and half in another of the same type. Although this renders the grouping improper according to the definition stated above, and according to the rule strictly adhered to in the tests carried out without the manostat, the index of dispersion for these two groups remained under \pm 1.0 , with several days elapsing between the first and the last of the tests in each case.

Each of the groups included in table 1 represents distinctly unique conditions with respect to at least one of the following particularsnamely, the length of the cooking interval selected (as determined by the bore of the burner nozzle used in conjunction with the other parts of the apparatus), the form of burner employed, the particular boiling vessel used, or the weight of the sample and the dimensions of all of the apparatus employed. Additional experimental data will be given in forthcoming papers.

The principal dimensions of the balanced double valve incorporated in the manostat illustrated in figure 3 are as follows: Thickness of orifice plates, approximately $1 \mathrm{~mm}$; bore of holes, $2.0-\mathrm{mm}$ drill (walls cylindrical, not beveled); major diameter of the spindles, $1.8 \mathrm{~mm}$; minor diameter of the spindles and diameter of the spindle stems, $0.9 \mathrm{~mm}$. The gas outlet is indicated at 0 . An annular atmospheric opening to the hydrostatic reservoir, $J_{1}$, is located at $Z_{1}$, just under the float-well cover, $F W$. The tubular atmospheric opening to the reservoir, $J_{2}$, is seen at $Z_{2}$. The liquid is an "odorless, tasteless, and colorless" mineral oil of the following specifications: Viscosity, 80/90 sec, or 0.245 poises at $25^{\circ} \mathrm{C}$; specific gravity at $25^{\circ} \mathrm{C}, 0.864$; flashpoint, $171^{\circ} \mathrm{C}$; burning point, $207^{\circ} \mathrm{C}$; acidity ( $\mathrm{mg}$ of $\mathrm{KOH} / \mathrm{g}$ of oil), none; sulfur, none; oxidation number, 0 ; gum on heating in oxygen, none; discoloration on heating in oxygen, slight orange. The service gas referred to is a carbureted manufactured water gas containing approximately 30 percent of natural gas. It has practically a constant heating value of $600 \mathrm{Btu}$ to the cubic foot.

In the first models of the flow manostat, which are not illustrated, the float-and-spindle assembly was rotated continuously during operation by the action of the incoming gas upon a turbine mounted on the stem of the spindle. The purpose of this arrangement was to prevent any possible sticking of the stem of the spindle in the bearings, sufficient to impede the requisite vertical movement. This precaution was found unnecessary, however, when oil was used as the liquid. Besides keeping the working parts lubricated, the oil seems to delay or prevent the accumulation of deposits from the gas. Moreover, the surface properties of the oil are more favorable than those of water, which served as the liquid in the first models. Finally, evaporation of the oil is entirely negligible.

\section{SUMMARY}

A basic design has been presented for the construction of a flow manostat with a floating orifice modulator which, in conjunction with external nozzles (or equivalent devices having constant-discharge characteristics) with which the manostat is to be employed, serves to 
regulate the flow of a gas from a source having a moderately variable pressure. The device is designed particularly for use in candy tests for the regulation of the output performance of a gas burner or a fixed group of simultaneously operating burners, but it can be utilized for numerous other purposes as well. It is properly a pressure-reducing valve, for the maximum regulated pressure must be less than the minimum service pressure at the source with which it is connected. Means are provided for varying the regulated pressure as well as the volume of the flow.

\section{REFERENCES}

[1] A. C. Robertson, Ind. Eng. Chem., Anal. Ed. 3, 383 (1931).

[2] NBS Circular C440 (1942).

[3] J. A. Ambler and S. Byall, Ind. Eng. Chem., Anal. Ed. 1, 169 (1935).

Washington, June 12, 1942. 